\title{
Bmp7 Regulates Germ Cell Proliferation in Mouse Fetal Gonads
}

\author{
A. Ross S. Munger B. Capel \\ Department of Cell Biology, Duke University Medical Center, Durham, NC, USA
}

\section{Key Words}

Bmp7 · Germ cells · Gonad development · Proliferation

\begin{abstract}
Relatively little is known regarding the signals that regulate the proliferation and sex-specific development of germ cells during mammalian fetal gonad differentiation. Members of the bone morphogenetic protein (BMP) family have been identified as key regulators of germ cells in the Drosophila gonad. Here we show that in mice $B m p 7$ is expressed in gonads of both sexes and is required for germ cell proliferation during a narrow window of development between 10.5-11.5 days post coitum (dpc). The proliferation defect is more severe in male than in female embryos suggesting that there are sexually dimorphic compensatory pathways. BMP signaling appears to be an evolutionarily conserved pathway regulating embryonic germ cell proliferation in vertebrate and invertebrate species.

Copyright $\odot 2007$ S. Karger AG, Basel
\end{abstract}

In the mouse, a population of primordial germ cells (PGCs) is first detectable at approximately 7.25 days post coitum (dpc) in a region posterior to the primitive streak [Ginsburg et al., 1990]. PGCs migrate through the hindgut into the urogenital ridges and populate the gonads between 10.0 and $11.0 \mathrm{dpc}$. Molecular signals have been identified that are required for the proliferation or sur- vival of PGCs during their migratory phase, including Kit ligand and stromal cell derived factor 1 (Sdf1) [Loveland and Schlatt, 1997; Ara et al., 2003]. In addition, numerous factors have been shown to stimulate PGC proliferation and/or survival in vitro, including Kit ligand, FGFs, leukemia inhibitory factor (LIF), tumor-necrosis factor (TNF) and interleukin-4 (IL4) [Matsui et al., 1992; Resnick et al., 1992; Kawase et al., 1994; Cooke et al., 1996]. However, it is not clear what roles these factors have in regulating germ cell proliferation in fetal gonads in vivo.

The developmental fate of germ cells is dependent upon their somatic environment, and not on their chromosomal composition [Adams and McLaren, 2002]. When PGCs initially enter the urogenital ridges, the gonads are bipotential, with the ability to form either an ovary or a testis. Sexually divergent development begins between 10.5 and $12.0 \mathrm{dpc}$, when the Y-linked gene Sry is expressed in somatic cells of the XY gonad and triggers testis development. Germ cells entering an XX or XY gonad proliferate until approximately $14.0 \mathrm{dpc}$, when germ cells in XX gonads enter prophase of meiosis and germ cells in XY gonads arrest in mitosis and initiate differentiation as prospermatogonia. Recently, differences in gene expression and motility of germ cells in XX and XY

This work was supported by grants from the NIH to A.R. (HD4131702) and B.C. (HD39963).

\section{KARGER}

Fax +4161306 1234

E-Mail karger@karger.ch

www.karger.com
(C) 2007 S. Karger AG, Basel

1661-5425/07/0012-0127\$23.50/0

Accessible online at:

www.karger.com/sxd
Blanche Capel

Department of Cell Biology, Duke University Medical Center

Durham, NC 27710 (USA)

Tel. +1 919684 6390, Fax +1 9196683467

E-Mail b.capel@cellbio.duke.edu 
gonads have been demonstrated as early as $11.5 \mathrm{dpc}$, suggesting that sex-specific germ cell development initiates shortly after expression of Sry begins [Takasaki et al., 2000; Molyneaux et al., 2001; Siggers et al., 2002; Menke et al., 2003; DiNapoli et al., 2006].

Currently, there is limited information regarding the signals that regulate the proliferation and differentiation of germ cells once they have populated embryonic gonads. Bone morphogenetic proteins (BMPs) are members of the TGF $\beta$ superfamily of secreted signaling molecules that have numerous roles in the regulation of germ cell development in both invertebrate and vertebrate species. In Drosophila, two homologs of mammalian BMPs, decapentaplegic ( $(\mathrm{pp})$ ) and glass bottom boat ( $\mathrm{gbb}$, also called $60 \mathrm{~A}$ ), are required for the maintenance and proliferation of germline stem cells [Xie and Spradling, 1998; Shivdasani and Ingham, 2003; Kawase et al., 2004]. In the mouse, BMPs have been shown to regulate germ cell development both during embryogenesis and in the adult. $B m p 2, B m p 4$, and $B m p 8 b$ are all involved in the regulation of PGC specification in the epiblast, and targeted inactivation of any of these genes results in reduced numbers of PGCs [Lawson et al., 1999; Ying et al., 2000; Ying and Zhao, 2001]. Mice homozygous for null mutations in either $B m p 8 a$ or $B m p 8 b$ or heterozygous for a mutation in $B m p 4$ display defects in spermatogenesis and germ cell survival in the adult testis [Zhao et al., 1996, 1998; Hu et al., 2004]. Two other members of the BMP family, growth differentiation factor 9 (GDF9) and BMP15, are required for normal oocyte development [Dong et al., 1996; Yan et al., 2001]. However, no functional roles for this family of signaling molecules during fetal gonad development have previously been described.

BMP2 and BMP4 are the mammalian BMPs most closely related to Drosophila Dpp, whereas Gbb is part of a subfamily of BMPs that also includes BMP5, BMP6, BMP7, BMP8a and BMP8b. Expression of Bmp2 has been reported previously specifically in murine XX gonads, starting at approximately $11.5 \mathrm{dpc}$ [Yao et al., 2004]. The early embryonic lethality of the $B m p 2$ mutants prevented any analysis of its function during this developmental period. In a survey of Gbb family members, we found that $B m p 7$ is expressed in embryonic gonads of both sexes prior to $11.5 \mathrm{dpc}$. However, at $12.5 \mathrm{dpc}$, expression is restricted to XY gonads based on in situ hybridization. Bmp7 mutants have numerous defects, including disrupted kidney, eye and skeletal development, and the homozygous mutants die shortly after birth [Dudley et al., 1995; Luo et al., 1995; Hofmann et al., 1996]. A role for Bmp7 in germ cell development in the adult testis has previously been described [Zhao et al., 2001]. Removal of one allele of $B m p 7$ on a Bmp8a homozygous mutant background results in a more severe spermatogenesis defect than that observed in the $B m p 8 a^{-/-}, B m p 7^{7^{++}}$mice. The exact functions of $B m p 7$ in the adult testis are not well understood, and the perinatal lethality of the homozygous mutants precludes a more detailed analysis of the function of this gene during spermatogenesis. Interestingly, when we examined germ cell development in $B m p 7^{-1-}$ mutant embryos, we identified a requirement for $B m p 7$ in the regulation of the early rounds of PGC proliferation, more severe in $\mathrm{XY}$ than in $\mathrm{XX}$ fetal gonads.

\section{Materials and Methods}

\section{Mice}

Heterozygous Bmp7 mutant mice, strain B6.129S7-Bmp7tm1Kry / J [Luo et al., 1995], were obtained from The Jackson Laboratory (stock number 003783). To genotype the mice, tail samples were incubated in digestion buffer $(0.05 \mathrm{M}$ Tris at $\mathrm{pH} 7.5,0.1 \mathrm{M}$ EDTA, $0.5 \% \mathrm{SDS}, 50 \mu \mathrm{g} / \mathrm{ml}$ Proteinase $\mathrm{K}$ ) at $55^{\circ} \mathrm{C}$ overnight. DNA was prepared for PCR by phenol:chloroform extraction and ethanol precipitation. The PCR primer sets were IMR801: GGCAAAGGATGTGATACGTGGAAG; IMR802: CCAGTTTCACTAATGACACAAACA; BMP7E7F: GTTCACTTCATCAACCCAGACACAGT; BMP7E7R: ACGAAGTTATTAGGTCCCTCGAC. Primers IMR801 and IMR802 amplify an 830-bp product from the mutant allele, and primers BMP7E7F and BMP7E7R amplify a 598-bp product from the wild-type allele. Timed matings were performed by housing heterozygous female mice with heterozygous males overnight and checking for vaginal plugs in the morning ( $0.5 \mathrm{dpc}$ is noon on the day after the vaginal plug is found).

\section{5 dpc Testis and Ovary Histology}

For general histology, testes and ovaries were fixed in Bouin's fluid overnight at $4^{\circ} \mathrm{C}$. After fixation, samples were dehydrated through a graded ethanol series, cleared with Histoclear (National Diagnostics, Atlanta, Ga, USA), and embedded in paraffin wax. Five $\mu \mathrm{m}$ sections were cut, stained using the Schiff's Periodic Acid Staining Kit (Polysciences, catalog \# 24200), following the kit instructions, and counterstained with hematoxylin.

\section{Alkaline Phosphatase Staining}

Samples were fixed in $4 \%$ paraformaldehyde at $4{ }^{\circ} \mathrm{C}$ overnight. The tissue was washed twice briefly in PBS containing $0.1 \%$ Tween-20 then washed in 70\% EtOH for several hours at room temperature. To detect alkaline phosphatase activity, samples were incubated in Fast Red stain $(0.5 \mathrm{mg} / \mathrm{ml}$ Fast Red TR, $0.1 \mathrm{mg} /$ $\mathrm{ml}$ naphthyl phosphate, $500 \mathrm{~mm}$ borax, $5 \mathrm{mM} \mathrm{MgCl}_{2}$ ) for $15 \mathrm{~min}$ at room temperature, or until staining was visible, and washed twice in PBS to stop the staining reaction.

\section{Immunohistochemistry}

For whole mount immunostaining, samples were fixed overnight in $4 \%$ paraformaldehyde in PBS at $4{ }^{\circ} \mathrm{C}$. Tissue was blocked for $1 \mathrm{~h}$ at room temperature in blocking solution $(10 \%$ heat inac- 
tivated goat serum, $0.1 \%$ Triton-X 100 in PBS). Primary antibody incubations were carried out overnight at $4^{\circ} \mathrm{C}$ in blocking solution (1:200 dilution of rabbit anti-laminin 1 antibody, provided by Harold Erickson; 1:500 dilution of rat anti-PECAM-1 antibody, Pharmingen; 1:250 dilution of rabbit anti-phosphorylated histone H3, Upstate Biotechnology; 1:100 dilution of rabbit anti-active caspase-3, Pharmingen). Gonads were washed 3 times in washing solution $(\mathrm{PBS} / 1 \%$ heat inactivated goat serum $/ 0.1 \%$ Triton-X 100$)$ for $1 \mathrm{~h}$ each. Secondary antibody incubations were performed overnight at $4^{\circ} \mathrm{C}$ with 1:500 dilution of fluorescently conjugated secondary antibodies (FITC- or Cy5-conjugated goat anti-rabbit antibody and Cy3-conjugated goat anti-rat antibody, Jackson Immunochemicals). Samples were washed 3 times for $1 \mathrm{~h}$ each in washing solution and mounted on glass slides in DABCO.

\section{In situ Hybridization}

Gonads were fixed in $4 \%$ paraformaldehyde at $4^{\circ} \mathrm{C}$ overnight. Samples were washed in PBST (PBS with $0.1 \%$ Tween-20) and treated with $10 \mu \mathrm{g} / \mathrm{ml}$ Proteinase $\mathrm{K}$ in PBST at $37^{\circ} \mathrm{C}$ for $15 \mathrm{~min}$. The tissue was fixed in $4 \%$ paraformaldehyde $/ 0.1 \%$ glutaraldehyde at room temperature for $15 \mathrm{~min}$ and washed twice with PBST. Samples were incubated in hybridization buffer $(50 \%$ formamide, $2 \times$ SSC, $0.5 \%$ CHAPS, $0.2 \%$ Tween $-20,1 \mathrm{mg} / \mathrm{ml}$ yeast tRNA, $50 \mu \mathrm{g} / \mathrm{ml}$ heparin, and $5 \mathrm{mM}$ EDTA) for $1 \mathrm{~h}$ at $60^{\circ} \mathrm{C}$, probe was added to hybridization buffer and samples were incubated for at least $24 \mathrm{~h}$ at $60^{\circ} \mathrm{C}$. Samples were washed once for $30 \mathrm{~min}$ at $60^{\circ} \mathrm{C}$ in $50 \%$ formamide, $2 \times$ SSC, $0.1 \%$ Tween-20, and twice for $30 \mathrm{~min}$ at $60^{\circ} \mathrm{C}$ in $2 \times$ SSC, $0.1 \%$ Tween-20. Samples were washed in MABT (100 mM Maleic acid, $150 \mathrm{~mm} \mathrm{NaCl}, 0.1 \%$ Tween-20, pH 7.5), then blocked in MABT containing 2\% Blocking Reagent (Roche, cat\# 1096176), and incubated overnight at $4{ }^{\circ} \mathrm{C}$ with antiDIG-AP antibody (Roche, cat\# 1093274) diluted 1:2000 in the blocking reagent. Samples were washed 3 times, $1 \mathrm{~h}$ each, with MABT and incubated with NBT/BCIP (Roche, cat\# 1681451) until color developed.

Sense and antisense probes were synthesized from plasmids containing full or partial cDNAs of the following: Oct4 (NM 013633: bases 183-1286, a gift from David Page), and $B m p \overline{7}$ (0.65-kb EcoRI/NotI fragment from I.M.A.G.E. clone 4218495). I.M.A.G.E. clone 4218495 consists of sequence from the $5^{\prime}$ UTR and first exon specific to $B m p 7$. The $B m p 7$ sense probe gave no signal, and the antisense probe gave staining patterns in the kidneys and limb buds that matched published data [Lyons et al., 1995].

To deplete gonads of germ cells for in situ hybridizations, pregnant females were injected IP with $100 \mu$ l busulfan solution (16 $\mathrm{mg} / \mathrm{ml}$ in $50 \%$ DMSO) or $50 \%$ DMSO (control) at $10.5 \mathrm{dpc}$. Embryos from the injected females were obtained at $13.5 \mathrm{dpc}$ and gonads isolated and prepared as described above for in situ hybridization for Oct4 or Bmp7.

\section{Germ Cell Counts}

Total numbers of germ cells in $10.5 \mathrm{dpc}$ urogenital ridges were counted using a light microscope after staining for alkaline phosphatase activity, as described above. For all later developmental stages, germ cells were counted in at least 3 different samples for each genotype and sex using a previously described method [Schmahl et al., 2000]. Briefly, gonads were stained using antibodies against PECAM-1 and imaged using the Zeiss LSM 410 confocal microscope. Longitudinal sections from the central third of each gonad were selected. For each sample, all PECAM-1-positive cells were counted in at least 4 sections spaced $15 \mu \mathrm{m}$ apart to avoid counting the same cells more than once. To quantitate the percentage of mitotic germ cells at each stage, the number of germ cells in each section positive for both phosphorylated histone $\mathrm{H} 3$ and PECAM-1 labeling were counted and divided by the total number of PECAM-1-positive germ cells in the section. For statistical comparisons of total germ cell numbers and percentages of mitotic cells, the results were analyzed using unpaired Student's t test and results were graphed using MS Excel.

\section{RNA Extraction and Reverse Transcription}

Total RNA was extracted from 12.5-dpc CD-1 gonads using TRIzol reagent (Invitrogen, cat\# 15596-026) as directed by the manufacturer, and eluted with $16 \mu \mathrm{l}$ RNAse-free water. To prevent DNA contamination, RNA was treated with $2 \mu \mathrm{l}$ DNase I and $2 \mu l 10 \times$ DNase I Reaction Buffer (Sigma, cat\# AMP-D1) at room temperature for $15 \mathrm{~min}$. DNase was inactivated by treatment with $2 \mu \mathrm{l}$ DNase I Stop Solution (Sigma, cat\# AMP-D1) at $70^{\circ} \mathrm{C}$ for 10 min. RNA was reverse transcribed into cDNA in a $20-\mu l$ reaction using the iScript ${ }^{\mathrm{TM}} \mathrm{cDNA}$ Synthesis Kit (Bio-Rad, cat\# 170-8890) according to the manufacturer's protocol.

\section{Quantitative RT-PCR}

Quantitative RT-PCR was used to determine relative expression levels of Bmp2, Bmp4, Bmp5, Bmp6, Bmp7, Bmp8a, and $B m p 8 b$ in 12.5-dpc CD-1 gonads. Each analysis was performed in triplicate in a total volume of $25 \mu \mathrm{l}$ reaction mixture containing $1 \mu \mathrm{l}$ cDNA template (1/20th of reverse transcription reaction), $12.5 \mu \mathrm{l} 2 \times \mathrm{iQ}^{\mathrm{TM}} \mathrm{SYBR}^{\circledR}$ Green Supermix (Bio-Rad, cat\# 170 $8880), 10.5 \mu \mathrm{l}$ RNase free water, and $0.5 \mu$ l each gene specific forward and reverse primer (500 nM final concentration each). Quantitative PCR was performed on the iCycler ${ }^{\mathrm{TM}}$ Thermal Cycler (Bio-Rad, cat\# 170-8720) with MyiQ ${ }^{\mathrm{TM}}$ Single-Color RealTime Detection System (Bio-Rad, cat\# 170-9740). PCR cycling conditions for all primers were as follows: $95^{\circ} \mathrm{C}$ for $3 \mathrm{~min} 30 \mathrm{~s}$ (one cycle); $95^{\circ} \mathrm{C}$ for $30 \mathrm{~s}, 60^{\circ} \mathrm{C}$ for $45 \mathrm{~s}, 72^{\circ} \mathrm{C}$ for $45 \mathrm{~s}$ ( 40 cycles); and $72^{\circ} \mathrm{C}$ for $2 \mathrm{~min}$ (one cycle). $\beta$-actin primers: Forward (5'-GGCTGTATTCCCCTCCATCG- $3^{\prime}$ ) and Reverse (5'-CCAGTTGGTAACAATGCCATGT-3'), Bmp2 primers: Forward (5'-AAGCGTCAAGCCAAACACAAA-3') and Reverse (5'-GAGTTCAGGTGGTCAGCAAGG-3'), Bmp4 primers: Forward (5'-TTCCTGGTAACCGAATGCTGA- $3^{\prime}$ ) and Reverse (5'-CCTGAATCTCGGCGACTTTTT- $3^{\prime}$ ), Bmp5 primers: Forward (5'-AGCCTGCAAGAAGCACGAAC- $3^{\prime}$ ) and Reverse (5'-AAAAGAACATTCCCCGTCACAA-3'), Bmp6 primers: Forward (5'-CAACGCCCTGTCCAATGAC-3') and Reverse (5'-ACTCTTGCGGTTCAAGGAGTG-3'), Bmp7 primers: Forward (5'-GATTTCAGCCTGGACAACGAG-3') and Reverse (5'-GGGCAACCCTAAGATGGACAG-3'), Bmp $8 a$ primers: Forward (5'-TTCTGGTCCTTTCCCAGTTCC-3') and Reverse (5'-TTCCAGGGCCTTCTTAGACCA-3'), and $B m p 8 b$ primers: Forward (5'-CTTTCCTGAAGACCCCCAACA-3') and Reverse (5'-TGGAGGTAGGTTGGAGCTTGG-3'). Primer sets were tested for efficiency and found to work optimally with the $\Delta \mathrm{Ct}$ method. The Ct number, defined as the number of PCR amplification cycles required to reach fluorescent intensity above threshold, was determined for each Bmp and the housekeeping gene $\beta$-actin. Normalized expression levels were obtained by subtracting the $\beta$-ac- 

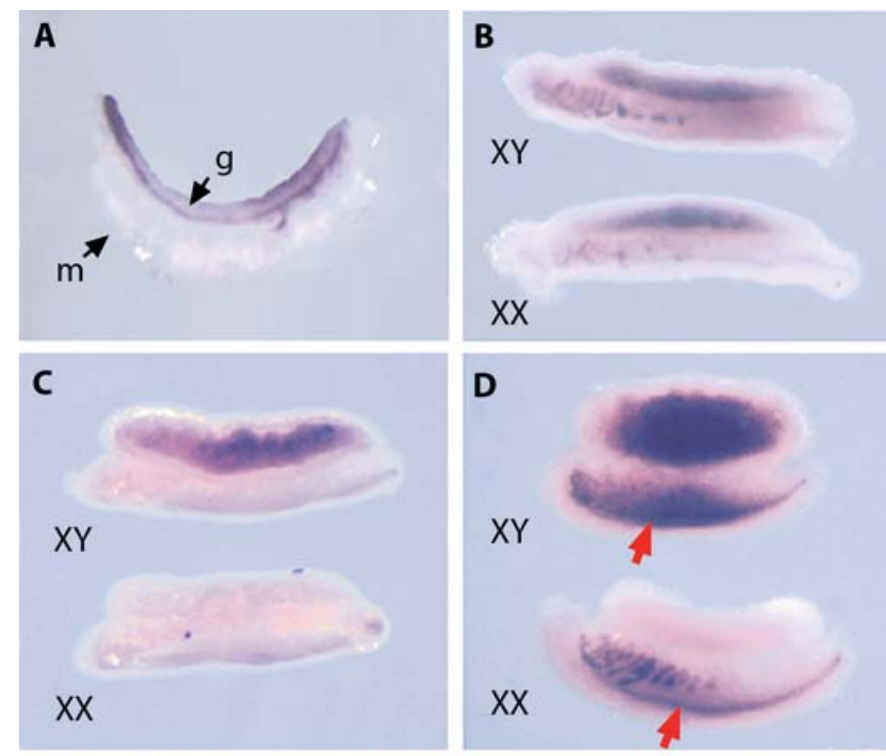

E

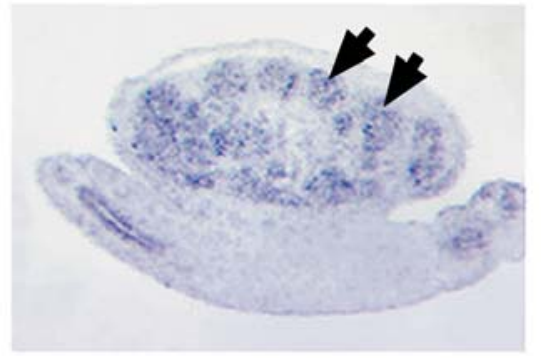

$\mathbf{F}$

Oct4

Bmp7

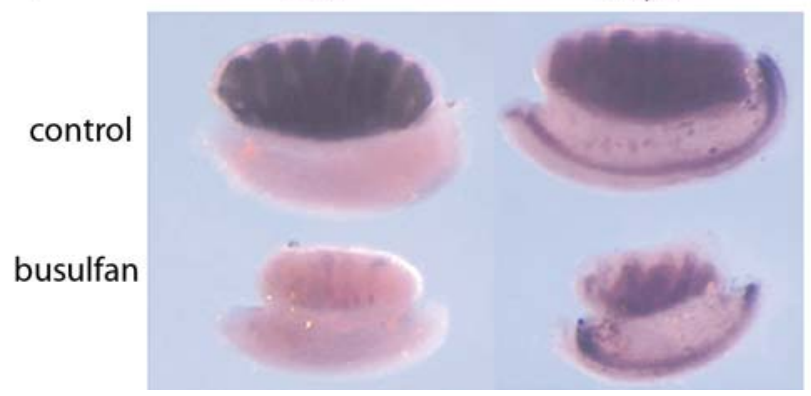

Fig. 1. Expression of $B m p 7$ during murine gonad development. A-F In situ hybridization was performed on whole mount gonads (g) and mesonephroi (m) at (A) $10.5 \mathrm{dpc}$, (B) $11.5 \mathrm{dpc}$, (C) $12.5 \mathrm{dpc}$, and (D) $13.5 \mathrm{dpc}$. Strong Bmp7 expression is observed in gonads of both sexes at 10.5 and $11.5 \mathrm{dpc}(\mathbf{A}, \mathbf{B})$. Bmp7 expression is downregulated in XX gonads by $12.5 \mathrm{dpc}$, but remains strong in $\mathrm{XY}$ gonads at 12.5 and $13.5 \mathrm{dpc}(\mathbf{C}, \mathbf{D})$. Expression of $B m p 7$ is also observed in the mesonephros (D, red arrows). E In situ hybridization of $B m p 7$ on sections of 13.5-dpc XY gonads. Expression is restricted to testis cords (black arrows). F In situ hybridization on 13.5$\mathrm{dpc} X Y$ control gonads and gonads depleted of germ cells. Staining for the germ cell marker Oct4 demonstrates the loss of germ cells in gonads from mice treated with busulfan. Bmp7 expression remains strong in the busulfan-treated gonads. tin $\mathrm{Ct}$ value from the Ct value obtained for each Bmp. Relative Bmp expression levels were obtained by comparing each normalized expression value to that of the lowest expressed $B m p$ in the set (in this case $B m p 8 b$ from the XY gonad).

\section{Results}

Expression of Bmp7 during Early Gonad Development Expression of $B m p 7$ was detected by ISH in the indifferent gonads as early as $10.5 \mathrm{dpc}$ (fig. $1 \mathrm{~A}$ ). $B m p 7$ was expressed in both XX and XY gonads through $11.5 \mathrm{dpc}$, after which stage it was detected only in $\mathrm{XY}$ gonads (fig. 1B, C, D). Bmp7 expression was maintained in XY gonads and was localized to testis cords at $13.5 \mathrm{dpc}$ (fig. 1E) and all later stages examined, from $15.5 \mathrm{dpc}$ until birth (not shown). Bmp7 was also expressed in the mesonephros, within the mesonephric duct and tubules (fig. 1D, red arrows).

Two cell types are found within testis cords, germ cells and Sertoli cells, the somatic supporting cells of the testis. The expression of $B m p 7$ within testis cords suggests that these genes are expressed by either germ cells, Sertoli cells, or both. To gain information regarding which cell type(s) express $B m p 7$, we used gonads from busulfantreated embryos, which lack germ cells, for in situ hybridization (fig. 1F). Bmp7 expression was very strong in testes lacking germ cells, demonstrating that $B m p 7$ is expressed by Sertoli cells. Importantly, this result does not rule out the possibility that $B m p 7$ is also expressed by germ cells. Germ cells have been shown to express $B m p 7$ at later developmental stages; specifically, in spermatogonia and spermatocytes in the adult testis [Zhao et al., 2001].

\section{Reduced Germ Cell Numbers in Bmp7 Mutant Gonads}

To determine if $B m p 7$ plays an important role during gonad development, we examined mice homozygous for a null mutation of $B m p 7$. As $B m p 7$ mutants die perinatally, we examined testes and ovaries from homozygous mutants at a stage shortly before birth. At $18.5 \mathrm{dpc}$, the gross morphology of $B m \mathrm{p}^{-1-}$ testes and ovaries appeared similar to wild-type controls (not shown). Sections of ovaries and testes from $B m p 7$ mutants were also examined (fig. 2). No obvious defects were apparent in the mutant ovaries, and germ cells displayed the characteristic features of meiosis (fig. 2A-D). By contrast, a defect in $B m p 7$ mutant testes was immediately detected. Testes from $B m p 7$ mutants had tubules that contained few or no 
Fig. 2. Hematoxylin and PAS stained sections of testes and ovaries from 18.5-dpc Bmp7 mutants and controls. A, B, E, F Gross morphology of $B m p 7^{-1-}$ ovaries (B) and testes (F) appears similar to controls (A, E). C, D Higher magnification of ovary sections. Bmp $7^{-1-}$ ovaries appear similar to controls and the germ cells display normal morphological features of meiotic oocytes (arrows). G, H Bmp $7^{-1-}$ testes contain reduced numbers of prospermatogonia (large, pale, round cells, black arrows) as compared to controls, and many tubules that lack germ cells entirely (red arrows).
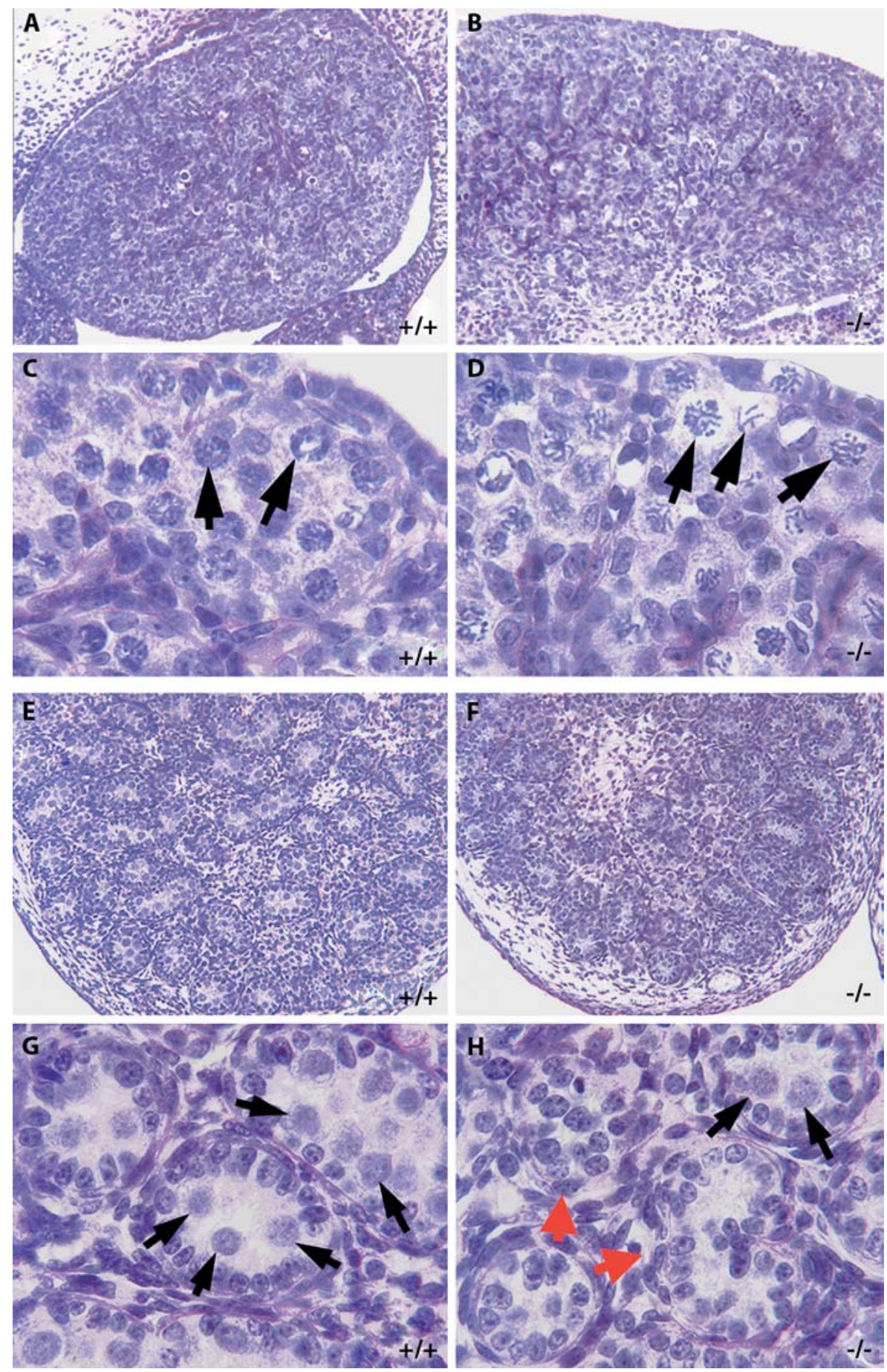

prospermatogonia, although the testes did not completely lack germ cells (fig. 2E-H). Other than the reduction in germ cell number, the organization and morphology of the mutant testes appeared normal.

Earlier stages of gonad development were examined to determine when the reduction in germ cells originates in the Bmp7 mutants. Gonads from 10.5 through 13.5 -dpc mutant and control embryos were stained for alkaline phosphatase activity, a marker of germ cells in both sexes at these stages (fig. 3A-F). There was no obvious visible difference in the appearance of XX or XY mutant gonads at $11.5 \mathrm{dpc}$ (fig. 3A, B). By $12.5 \mathrm{dpc}$, however, a pro- 


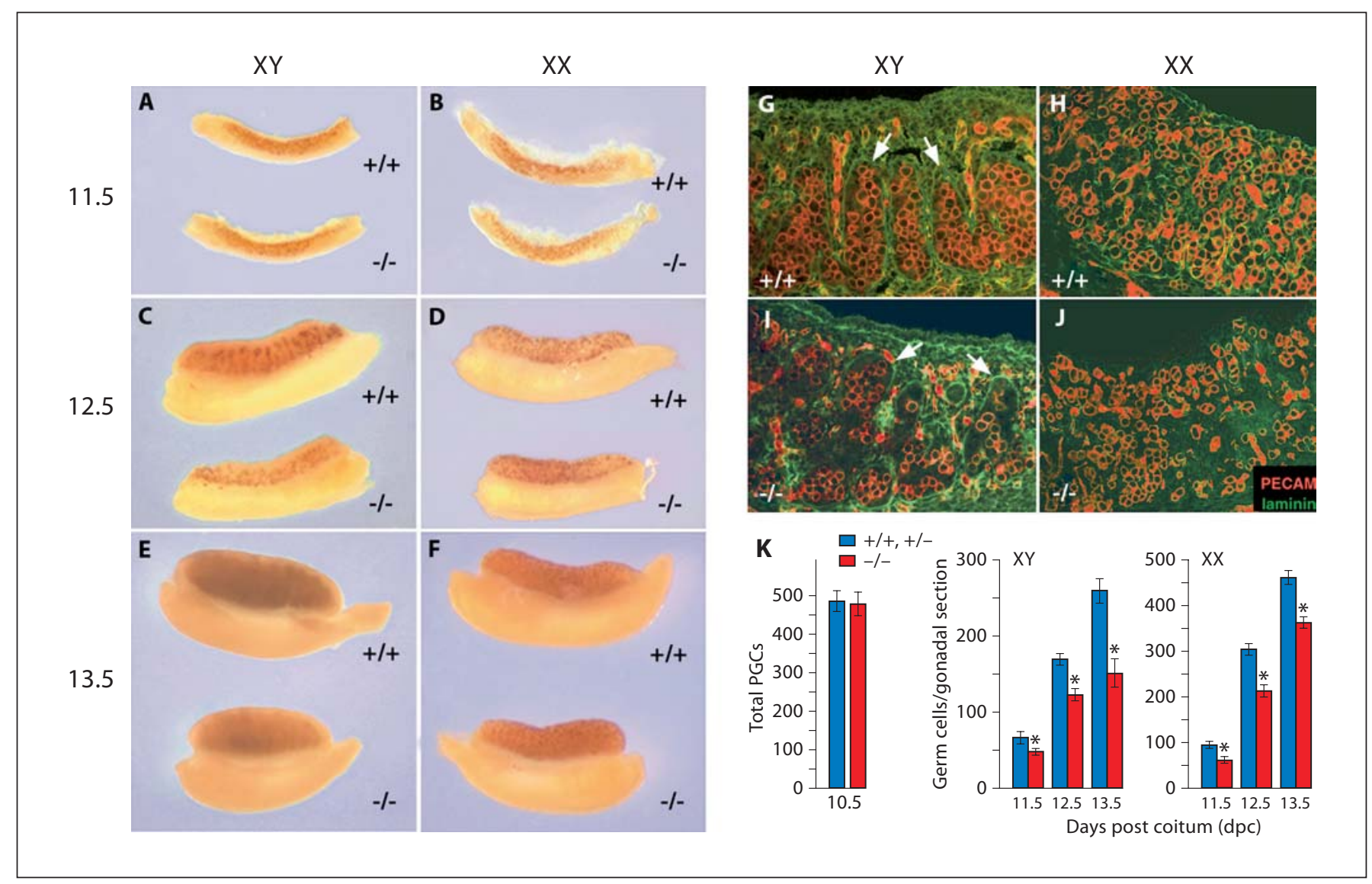

Fig. 3. The germ cell defect in $B m p 7$ mutants occurs during early stages of gonad development. A-F Gonads from $B m p 7$ mutant embryos and controls from 11.5 to $13.5 \mathrm{dpc}$ were stained for alkaline phosphatase activity (reddish-brown staining) to label germ cells. C, D A reduction in germ cell numbers is clearly visible in XY $B m p 7$ mutants by $12.5 \mathrm{dpc}$, whereas XX mutant gonads are slightly smaller in size than controls, but not as severely affected. E, F Similar differences were observed at $13.5 \mathrm{dpc}$, with both XX and XY mutant gonads smaller than controls. G-J Immunostaining for PECAM-1 (red, labels germ cells and elongated vascular endothelial cells) and laminin (green, outlines testis cords, white arrows) on gonads from 13.5- $\mathrm{dpc} B m p 7$ mutants and contols. G, I XY $B m p 7^{-/-}$gonads are morphologically similar to controls, but contain a lower density of germ cells. $\mathbf{K}$ Total germ cell numbers in 10.5-dpc mutant and control genital ridges and germ cells per longitudinal gonad section in embryos from 11.5 to $13.5 \mathrm{dpc}$. A statistically significant difference is first observed between mutants and controls at $11.5 \mathrm{dpc}$, and is detected at all later stages. Wild type and heterozygotes, blue bars; homozygous Bmp7 mutants, red bars. Values represent mean \pm s.e.m. * Statistically significant ( $\mathrm{p}<0.05$, Student's t test). 11.5-dpc XY controls $(\mathrm{n}=21$ gonads), XY mutants $(\mathrm{n}=25), \mathrm{XX}$ controls $(\mathrm{n}=14), \mathrm{XX}$ mutants $(n=15) ; 12.5-d p c X Y$ controls $(n=24), X Y$ mutants $(n=21), X X$ controls $(n=12)$, XX mutants $(n=12)$; 13.5-dpc XY controls $(n=18), X Y$ mutants $(n=17), X X$ controls $(n=20)$, XX mutants $(\mathrm{n}=20)$.
Fig. 4. Reduced proliferation of germ cells in $B m p 7^{-1-}$ gonads until $11.5 \mathrm{dpc}$. A-H Immunostaining of gonads with antibodies against phosphorylated histone $\mathrm{H} 3$ (red) to label mitotic cells and PECAM-1 (green), which labels germ cells (round) and vascular endothelial cells (elongated). Mitotic germ cells were identified as cells outlined in green with red nuclei (A, inset). A, B At $11.0 \mathrm{dpc}$, numerous mitotic germ cells (white arrows, round cells with both green and red staining) are observed in XX and XY gonads from wild-type embryos. C, D Few or no mitotic germ cells are observed in most sections from XX or XY Bmp7 mutant gonads at the same stage, but numerous mitotic somatic cells are still present (blue arrowheads), including PECAM-1-positive cells that can be identified as vascular endothelial cells based on their morphology (purple arrowhead). E-H At $12.5 \mathrm{dpc}$, there are fewer mitotic germ cells (white arrows) in XY mutant gonads as compared to controls, but there are also fewer total germ cells. Similar numbers of mi- 


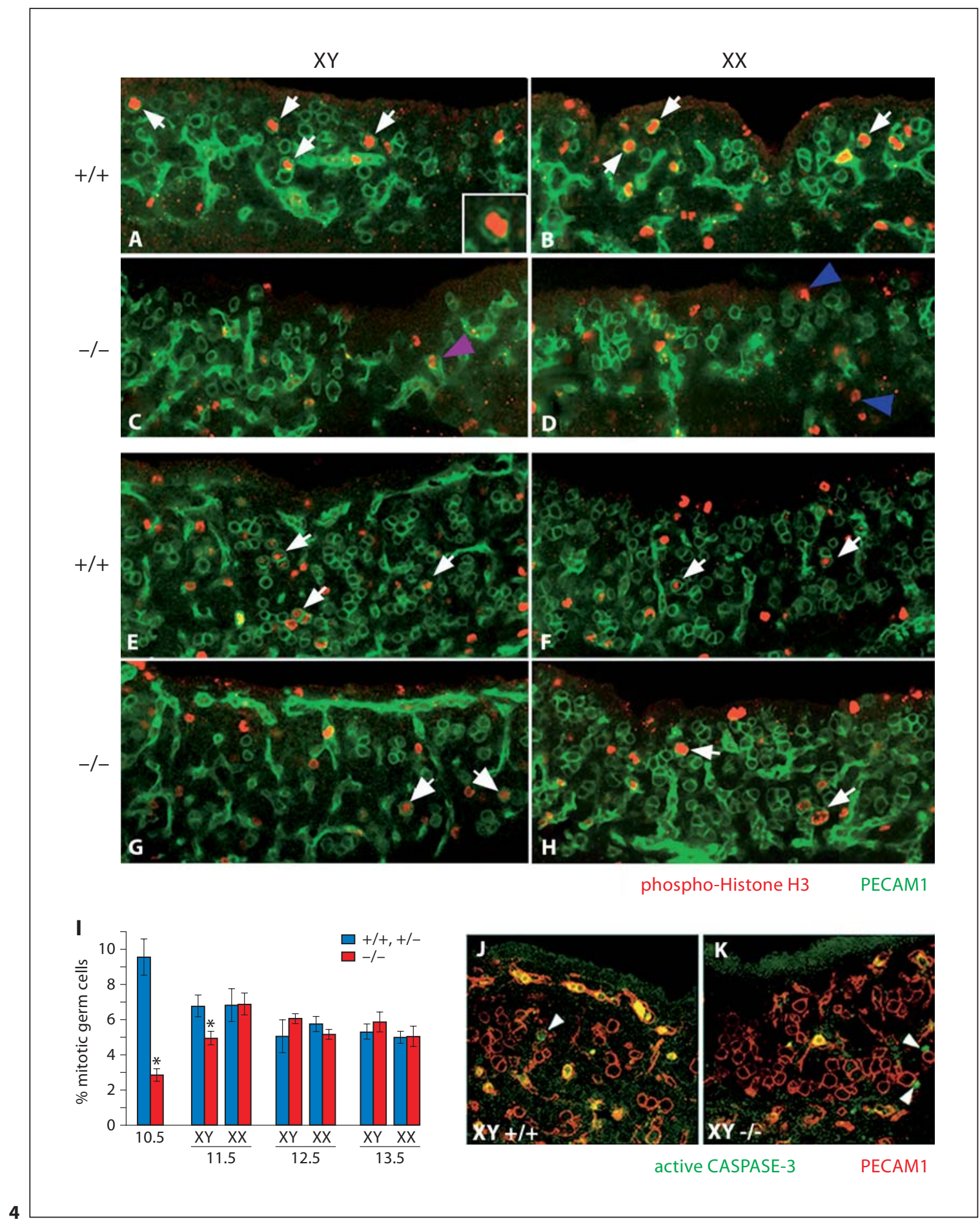

totic germ cells were observed in XX mutants and controls at this stage. I Percentage of germ cells positive for phospho-histone H3. A statistically significant reduction in the percentage of mitotic germ cells was observed in mutant gonads (XX and XY) as compared to controls at $10.5 \mathrm{dpc}(10.5$-dpc mutants, $\mathrm{n}=8$ gonads, controls $\mathrm{n}=10$ ). At $11.5 \mathrm{dpc}$, a small but significant reduction in mitotic germ cells was observed in mutant XY gonads, but not in $\mathrm{XX}$ gonads (11.5-dpc XY mutants, $\mathrm{n}=7$ gonads, $\mathrm{XY}$ controls $\mathrm{n}=$
8). At 12.5 and $13.5 \mathrm{dpc}$, rates of mitosis are similar in mutants and controls of both sexes. Values represent mean \pm s.e.m. ${ }^{*}$ Statistically significant ( $\mathrm{p}<0.05$, Student's t test). J, K Immunostaining for active caspase-3 (green) to label apoptotic cells (white arrowheads), and PECAM-1 (red) in 11.5-dpc XY Bmp7 mutant gonad and control. Few dying germ or somatic cells were detected in either mutant or control samples at any stage examined. 
nounced defect was observed in XY Bmp $7^{-/-}$gonads. At this stage, the XY mutant gonads were smaller than controls and showed reduced levels of alkaline phosphatase staining (fig. 3C). However, two markers of Sertoli cell development, Sox 9 and Dhh, were expressed normally in 12.5-dpc XY gonads, suggesting that differentiation of the somatic gonad was normal (ISH data not shown). By $13.5 \mathrm{dpc}$, the mutant testes were significantly smaller than controls and appeared to contain fewer germ cells, but were otherwise morphologically normal (fig. 3E). Bmp7 mutant XX gonads appeared to contain a similar density of germ cells as controls, but were slightly reduced in size (fig. 3D, F).

To confirm these results and enable better quantification of germ cell numbers, immunostaining for PECAM1 was performed. PECAM-1 (platelet/endothelial cell adhesion molecule 1) labels both germ cells and vascular endothelial cells in the embryonic gonads, but the two cell types can easily be distinguished based on shape and location. Sections of mutant gonads stained for PECAM1 contained a reduced number of germ cells, but appeared otherwise normal (fig. 3G-J). The phenotype was more striking when the extent of the germ cell reduction was quantified. Germ cell counts were performed on sections of mutant and control gonads stained with PECAM-1 at different developmental stages (fig. 3K). Of note, no statistical difference was found in germ cell number between wild-type and heterozygous gonads at any stage, so these genotype classes were combined and used as controls in these studies. At $10.5 \mathrm{dpc}$, there was no significant difference in germ cell numbers in the gonads of mutants and controls, suggesting that the initial specification and migration of germ cells to the urogenital ridge occurs normally. By $11.5 \mathrm{dpc}$, however, a small but significant $(p<0.05)$ reduction in germ cell numbers was found in both XX and XY mutants (Germ cells per section: XY controls, mean $=67 \pm 5, \mathrm{n}=21$ gonads; $\mathrm{XY}$ mutants, mean $=49 \pm 3, \mathrm{n}=25 ; \mathrm{XX}$ controls, mean $=98 \pm 4, \mathrm{n}=$ 14; XX mutants $66 \pm 5, \mathrm{n}=15$ ) (fig. 3). [Note that this result does not mean that total germ cell numbers are higher in XX than XY gonads, as XY gonads are larger than XX gonads at these stages.] Similar reductions in germ cell numbers were observed in the mutants at both $12.5 \mathrm{dpc}$ and $13.5 \mathrm{dpc}$ (fig. $3 \mathrm{~K}$ ). The effect was more pronounced in XY gonads than in XX. By $13.5 \mathrm{dpc}$, XX mutant gonads had an average of $78 \%$ the number of germ cells/section as compared to controls $(362 \pm 9, \mathrm{n}=20$ versus $462 \pm 16, \mathrm{n}=20$ ), whereas $\mathrm{XY}$ mutant samples contained an average of $58 \%$ the number of germ cells per section as controls $(152 \pm 17, \mathrm{n}=17$ versus $260 \pm 14$, $\mathrm{n}=18$ ). This is consistent with the qualitative results described above, in which the germ cell defect was more clearly visible in XY mutants than XX at both $13.5 \mathrm{dpc}$ (fig. 3E, F) and 18.5 dpc (fig. 2). Given that the mutant gonads are smaller than wild type and have fewer sections, the total numbers of germ cells present are further reduced.

\section{Reduced Levels of Germ Cell Proliferation in Bmp7 Mutants}

The reduction in germ cell number observed in $B m p 7$ mutants suggests that there is a defect in germ cell proliferation and/or survival. To investigate these possibilities, we examined the expression of markers of cell proliferation and cell death in gonads of $B m p 7$ mutants at different developmental stages. During mitosis, histone H3 is phosphorylated on its amino terminus (serine 10), and this phosphorylation event correlates with mitotic chromosome condensation [Hendzel et al., 1997; Wei and Allis, 1998]. We stained gonads from $B m p 7$ mutants and controls at stages from $10.5 \mathrm{dpc}$ to $13.5 \mathrm{dpc}$ with antibodies against PECAM-1 and phosphorylated histone $\mathrm{H} 3$ to identify proliferating germ cells (fig. $4 \mathrm{~A}-\mathrm{H}$ ). Gonads from $B m p 7$ mutants at 10.5 or 11.0 dpc displayed a striking reduction in the number of mitotic germ cells as compared to controls, as few or no germ cells positive for phosphorylated histone $\mathrm{H} 3$ were observed in most sections examined (fig. 4A-D). At all later stages examined, there were fewer mitotic germ cells in mutant gonads as compared to controls, but there were also fewer total germ cells (fig. 4E-H). The percentage of mitotic germ cells relative to total germ cell numbers was calculated, and it was discovered that there was a statistically significant reduction $(\mathrm{p}<0.05)$ in the mitotic index until $11.5 \mathrm{dpc}$ (fig. 4I). At $10.5 \mathrm{dpc}$, the average percentage of germ cells positive for phospho-histone $\mathrm{H} 3$ staining in control genital ridges was more than three times the amount observed in mutants $(9.0 \pm 1 \%, \mathrm{n}=10$ gonads versus $3.0 \pm 0.3 \%, \mathrm{n}=8)$. By $11.5 \mathrm{dpc}$, there was no significant difference in the percentage of mitotic germ cells in mutant XX gonads versus control XX gonads. However, there was still a small but statistically significant reduction in the percentage of mitotic germ cells in XY mutant gonads as compared to controls at this stage (XY controls: $6.8 \pm 0.7 \%, \mathrm{n}=8$ gonads; $\mathrm{XY}$ mutants: $4.9 \pm 0.3 \%, \mathrm{n}=7, \mathrm{p}=0.013)$. At 12.5 or 13.5 $\mathrm{dpc}$, the mitotic index was similar to controls in both XX and $\mathrm{XY}$ mutants (fig. $4 \mathrm{I}$ ). Thus, there is a transient requirement for $B m p 7$ for germ cell proliferation in embryonic gonads until approximately $11.5 \mathrm{dpc}$, lasting slightly longer in XY than XX gonads. 


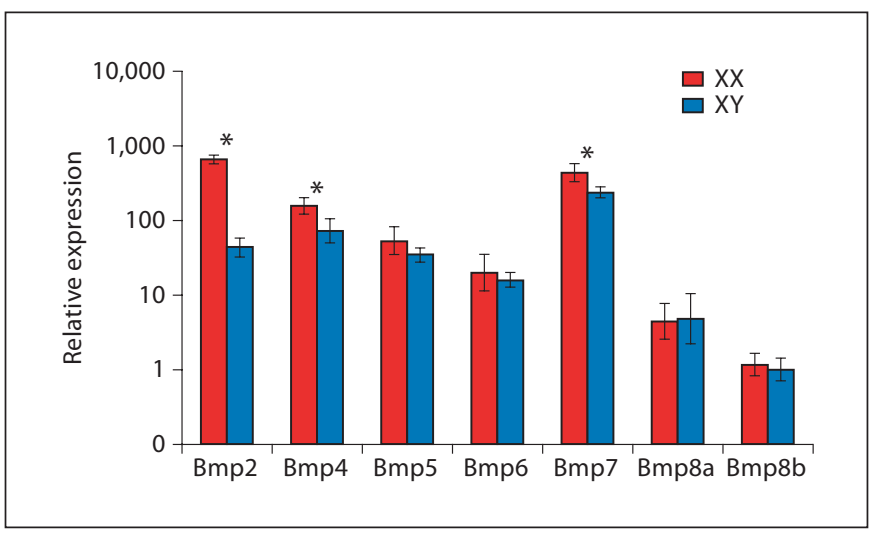

Fig. 5. Q-RT-PCR analysis of Dpp/Gbb family members in XX and XY 12.5-dpc CD-1 gonads. Bmp2, Bmp4, and Bmp7 show significantly higher levels of expression in XX than in XY gonads, whereas $B m p 5$, $B m p 6, B m p 8 a$, and $B m p 8 b$ all show similar levels of expression in XX and XY gonads. * Statistically significant $(\mathrm{p}<0.05$, Student's t test).

Markers of cell death were also examined to determine if there was a germ cell survival defect in the mutants. $B m p 7$ mutant gonads were labeled with antibodies against the active form of caspase-3, an early marker of apoptotic death, at stages from 10.5 to $12.5 \mathrm{dpc}$. Few apoptotic cells were observed in either mutants or controls at 11.5 dpc (fig. 4J, K) or other stages examined (not shown). Similar results were obtained using Lysotracker dye to label dying cells (not shown). Therefore, the reduced germ cell numbers in $B m p 7$ mutants appear to result from a proliferation defect manifest just as germ cells arrive in the urogenital ridge.

\section{Expression of Dpp/Gbb Family Members in Fetal Gonads}

The observation that the germ cell deficiency is more pronounced in XY than XX mutant gonads suggests that another BMP is compensating for loss of BMP7 in the XX mutant gonad. To investigate this possibility, we quantified the expression of $B m p 7$ and various other $D p p$ and $G b b$ family members in 12.5 -dpc wild-type gonads by quantitative RT-PCR (Q-RT-PCR). All have previously been found to be expressed in fetal gonads by microarray analysis [Nef et al., 2005; Small et al., 2005; Bouma et al., 2006].

Based on Q-RT-PCR analysis, expression of Bmp7 was found to be slightly higher in female than in male gonads (fig. 5). This finding is inconsistent with the in situ results. There are several possible explanations for this discrepancy which we are currently investigating: (1) per- haps different spliceoforms are detected by the in situ probe and the Q-RT-PCR primers; or (2) perhaps mRNA for $B m p 7$ is masked by RNA-binding proteins in XX but not XY gonads (we would argue that ISH might not detect these RNAs whereas they are detectable after Trizol extraction). Both $D p p$ family members, $B m p 2$ and $B m p 4$, were expressed at significantly higher levels in XX gonads than XY. The expression levels of other $G b b$ family members, $B m p 5$, Bmp6, $B m p 8 a$, and $B m p 8 b$, were not significantly different between XX and XY gonads. Any or all of these BMPs may partially compensate for loss of BMP7 during fetal gonad development.

\section{Discussion}

Functions for BMPs have been well characterized in the Drosophila testis and ovary, where Dpp and $G b b$ are required for the self-renewal of germline stem cells. We provide the first in vivo evidence that BMP signaling is required for the early rounds of PGC proliferation in mammalian fetal gonads. This finding is especially interesting, as it suggests that BMPs are conserved signals that regulate germ cell proliferation in very diverse organisms during multiple developmental stages.

$B m p 7$ mutants display a reduction in germ cell number in both XX and XY embryonic gonads, first detectable at about $11.5 \mathrm{dpc}$. The reduction results from a defect in germ cell proliferation that occurs between 10.5 and $11.5 \mathrm{dpc}$. This phenotype was observed in both sexes; however, the germ cell deficiency was more severe and the proliferation defect lasted slightly longer in XY mutant gonads than in XX. Thus, there are different requirements for BMP7 signaling in germ cells after the divergence of gonad development in XX and XY embryos, supporting the idea that sex-specific germ cell development initiates shortly after PGCs migrate into the gonads.

There may be different Bmps in XX and XY gonads that compensate for loss of $B m p 7$, with different efficiencies. Bmp2 is more highly expressed in XX gonads than in XY gonads at very early stages, starting between 11.0 and $11.5 \mathrm{dpc}$. Both BMP2 and its close relative BMP4 have mitogenic effects on germ cells in culture [Pellegrini et al., 2003; Puglisi et al., 2004]; thus, it is possible that BMP2 and/or BMP4 compensate for loss of Bmp7 in XX gonads during the period of time that their expression overlaps. A recent study showed that BMP4 was able to fully substitute for loss of BMP7 in the developing kidney, although these molecules share minimal sequence simi- 
larity [Oxburgh et al., 2005]. This could explain why the germ cell loss observed in XX $B m p 7$ mutant gonads is less severe than germ cell loss in XY mutants. Analysis at the protein level will be required to resolve this question; however, currently available BMP7 antibodies lack the specificity to obtain a clear result.

Proliferation of germ cells in XY gonads may be dependent on $B m p 7$ for a longer period of time. $B m p 5$, $B m p 6, B m p 8 a$, and $B m p 8 b$ are also expressed in gonads of both sexes at $12.5 \mathrm{dpc}$. These members of the Gbb family are very closely related to $B m p 7$ and could be functionally redundant with $B m p 7$, as has been shown in other cases. For example, mice that are double homozygous mutant for Bmp6 and Bmp7 display cardiac defects not observed in either of the single mutants [Kim et al., 2001]. Analysis of mice heterozygous or homozygous for various combinations of these genes would be required to address this possibility and reveal phenotypes not observed in the single mutants.

$B m p 7$ is only required for germ cell proliferation during a short developmental window. Interestingly, a recent study working with aggregates of neural stem cells in culture discovered that BMP7 was expressed during the early proliferative expansion of these cells [Deleyrolle et al., 2006]. However, a switch to expression of BMP4 and BMP6 occurred as the cells differentiated. Perhaps a similar switch occurs in the gonads, with BMP7 stimulating the early expansion of the germ cell population, and other BMPs regulating subsequent proliferation and/or differentiation. It is likely that multiple pathways synergize to regulate PGC proliferation and safeguard fertility. Future work will hopefully elucidate the coordinate roles of BMPs and other molecular signals in the regulation of germ cell development in the early gonad.

\section{Acknowledgements}

The authors would like to thank the following colleagues for generously providing antibodies or plasmids: Harold Erickson, Brigid Hogan, and David Page. We would also like to thank Humphrey Yao, Doug Coveney, Leo DiNapoli, Yuna Kim and Hao Tang for their helpful comments during the course of this work.

\section{References}

Adams IR, McLaren A: Sexually dimorphic development of mouse primordial germ cells: switching from oogenesis to spermatogenesis. Development 129:1155-1164 (2002).

Ara T, Nakamura Y, Egawa T, Sugiyama T, Abe $\mathrm{K}$, et al: Impaired colonization of the gonads by primordial germ cells in mice lacking a chemokine, stromal cell-derived factor-1 (SDF-1). Proc Natl Acad Sci USA 100:5319_ 5323 (2003).

Bouma GJ, Affourtit JP, Bult CJ, Eicher EM: Transcriptional profile of mouse pre-granulosa and Sertoli cells isolated from early-differentiated fetal gonads. Gene Expr Patterns 7:113-123 (2006)

Cooke JE, Heasman J, Wylie CC: The role of interleukin- 4 in the regulation of mouse primordial germ cell numbers. Dev Biol 174: 14-21 (1996)

Deleyrolle L, Marchal-Victorion S, Dromard C, Fritz V, Saunier M, et al: Exogenous and FGF2/EGF-regulated endogenous cytokines regulate neural precursor cell growth and differentiation. Stem Cells 24:748-762 (2006).

DiNapoli L, Batchvarov J, Capel B: FGF9 promotes survival of germ cells in the fetal testis. Development 133:1519-1527 (2006).
Dong J, Albertini DF, Nishimori K, Kumar TR, Lu N, Matzuk MM: Growth differentiation factor-9 is required during early ovarian folliculogenesis. Nature 383:531-535 (1996).

Dudley AT, Lyons KM, Robertson EJ: A requirement for bone morphogenetic protein-7 during development of the mammalian kidney and eye. Genes Dev 9:2795-2807 (1995).

Ginsburg M, Snow MH, McLaren A: Primordial germ cells in the mouse embryo during gastrulation. Development 110:521-528 (1990).

Hendzel MJ, Wie Y, Mancini MA, Van Hooser A, Ranalli T, et al: Mitosis-specific phosphorylation of histone $\mathrm{H} 3$ initiates primarily within pericentromeric heterochromatin during G2 and spreads in an ordered fashion coincident with mitotic chromosome condensation. Chromosoma 106:348-360 (1997).

Hofmann C, Luo G, Balling R, Karsenty G: Analysis of limb patterning in BMP-7-deficient mice. Dev Genet 19:43-50 (1996).

Hu J, Chen YX, Wang D, Qi X, Li TG, et al: Developmental expression and function of Bmp4 in spermatogenesis and in maintaining epididymal integrity. Dev Biol 276:158171 (2004).

Kawase E, Yamamoto H, Hashimoto K, Nakatsuji N: Tumor necrosis factor-alpha (TNFalpha) stimulates proliferation of mouse primordial germ cells in culture. Dev Biol 161: 91-95 (1994).
Kawase E, Wong MD, Ding BC, Xie T: Gbb/Bmp signaling is essential for maintaining germline stem cells and for repressing bam transcription in the Drosophila testis. Development 131:1365-1375 (2004).

Kim RY, Robertson EJ, Solloway MJ: Bmp6 and $B m p 7$ are required for cushion formation and septation in the developing mouse heart. Dev Biol 235:449-466 (2001).

Lawson KA, Dunn NR, Roelen BA, Zeinstra LM, Davis AM, et al: Bmp4 is required for the generation of primordial germ cells in the mouse embryo. Genes Dev 13:424-436 (1999).

Loveland K, Schlatt S: Stem cell factor and $c$-Kit in the mammalian testis: lessons originating from Mother Nature's knockouts. J Endocrinol 153:337-344 (1997)

Luo G, Hofmann C, Bronckers AL, Sohocki M, Bradley A, Karsenty G: BMP-7 is an inducer of nephrogenesis, and is also required for eye development and skeletal patterning. Genes Dev 9:2808-2820 (1995).

Lyons KM, Hogan BL, Robertson EJ: Colocalization of BMP-7 and BMP-2 RNAs suggests that these factors cooperatively mediate tissue interactions during murine development. Mech Dev 50:71-83 (1995).

Matsui Y, Zsebo K, Hogan BL: Derivation of pluripotential embryonic stem cells from murine primordial germ cells in culture. Cell 70:841-847 (1992) 
Menke DB, Koubova J, Page DC: Sexual differentiation of germ cells in XX mouse gonads occurs in an anterior-to-posterior wave. Dev Biol 262:303-312 (2003)

Molyneaux KA, Stallock J, Schaible K, Wylie C: Time-lapse analysis of living mouse germ cell migration. Dev Biol 240:488-498 (2001).

Nef S, Schaad O, Stallings NR, Cederroth CR, Pitetti JL, et al: Gene expression during sex determination reveals a robust female genetic program at the onset of ovarian development. Dev Biol 287:361-377 (2005).

Oxburgh L, Dudley AT, Godin RE, Koonce CH, Islam A, et al: BMP4 substitutes for loss of BMP7 during kidney development. Dev Biol 286:637-646 (2005)

Pellegrini M, Grimaldi P, Rossi P, Geremia R, Dolci S: Developmental expression of BMP4/ ALK3/SMAD5 signaling pathway in the mouse testis: a potential role of BMP4 in spermatogonia differentiation. J Cell Sci 116: 3363-3372 (2003).

Puglisi R, Montanari M, Chiarella P, Stefanini M, Boitani C: Regulatory role of BMP2 and BMP7 in spermatogonia and Sertoli cell proliferation in the immature mouse. Eur J Endocrinol 151:511-520 (2004).

Resnick JL, Bixler LS, Cheng L, Donovan PJ: Long-term proliferation of mouse primordial germ cells in culture. Nature 359:550551 (1992).
Schmahl J, Eicher EM, Washburn LL, Capel B: Sry induces cell proliferation in the mouse gonad. Development 127:65-73 (2000).

Shivdasani AA, Ingham PW: Regulation of stem cell maintenance and transit amplifying cell proliferation by Tgf-beta signaling in Drosophila spermatogenesis. Curr Biol 13:20652072 (2003).

Siggers P, Smith L, Greenfield A: Sexually dimorphic expression of Gata-2 during mouse gonad development. Mech Dev 111:159-162 (2002).

Small CL, Shima JE, Uzumcu M, Skinner MK, Griswold MD: Profiling gene expression during the differentiation and development of the murine embryonic gonad. Biol Reprod 72:492-501 (2005)

Takasaki N, McIsaac R, Dean J: Gpbox (Psx2), a homeobox gene preferentially expressed in female germ cells at the onset of sexual dimorphism in mice. Dev Biol 223:181-193 (2000).

Wei Y, Allis CD: A new marker for mitosis. Trends Cell Biol 8:266 (1998).

Xie T, Spradling AC: decapentaplegic is essential for the maintenance and division of germline stem cells in the Drosophila ovary. Cell 94:251-260 (1998).
Yan C, Wang P, DeMayo J, DeMayo FJ, Elvin JA, et al: Synergistic roles of bone morphogenetic protein 15 and growth differentiation factor 9 in ovarian function. Mol Endocrinol 15: 854-866 (2001).

Yao HH, Matzuk MM, Jorgez CJ, Menke DB, Page DC, et al: Follistatin operates downstream of Wnt4 in mammalian ovary organogenesis. Dev Dyn 230:210-215 (2004).

Ying Y, Zhao GQ: Cooperation of endoderm-derived BMP2 and extraembryonic ectodermderived BMP4 in primordial germ cell generation in the mouse. Dev Biol 232:484-492 (2001).

Ying Y, Liu XM, Marble A, Lawson KA, Zhao GQ: Requirement of $B m p 8 b$ for the generation of primordial germ cells in the mouse. Mol Endocrinol 14:1053-1063 (2000).

Zhao GQ, Deng K, Labosky PA, Liaw L, Hogan $\mathrm{BL}$ : The gene encoding bone morphogenetic protein $8 \mathrm{~B}$ is required for the initiation and maintenance of spermatogenesis in the mouse. Genes Dev 10:1657-1669 (1996).

Zhao GQ, Liaw L, Hogan BL: Bone morphogenetic protein $8 \mathrm{~A}$ plays a role in the maintenance of spermatogenesis and the integrity of the epididymis. Development 125:11031112 (1998).

Zhao GQ, Chen YX, Liu XM, Xu Z, Qi X: Mutation in $B m p 7$ exacerbates the phenotype of Bmp8a mutants in spermatogenesis and epididymis. Dev Biol 240:212-222 (2001). 